\title{
Hausärztin? Ich doch nicht!
}

Sarah Singer

Studentin im 5. Studienjahr

\footnotetext{
* Junge Hausärztinnen und -ärzte Schweiz (JHaS) www.jhas.ch

** Eine Art Stammtisch in einem Berner Restaurant, an dem sich regelmässig Studierende, Assistenzärzte und vereinzelt auch Hausärzte treffen.
}

Korrespondenz: cand. med. Sarah Singer Vorstandsmitglied JHaS Bündliweg 7 CH-4543 Deitingen

sarah.singer@jhas.ch

\section{Studienjahr}

Noch weiss ich nicht, was für eine Ärztin ich werden möchte. Ich finde alle Fächer sehr interessant. Vielleicht Neurologin oder Rechtsmedizinerin. Ganz sicher werde ich nicht Hausärztin. Das wird man nur, wenn man nichts Besseres weiss oder kann. Als Hausärztin ist man in erster Linie dazu da, Patienten zu impfen und den Blutdruck zu messen. Ich gehe schliesslich auch nur zum Impfen zum Arzt. Die pure Unterforderung. Kaum hat man einen spannenden Fall, muss man ihn abgeben und sieht ihn nie wieder. Von Fachärzten wird man belächelt. Und wie war das? Als Hausarzt verdient man sowieso nichts!

\section{Studienjahr}

Hausärztin zu werden ist mein Plan. Eine andere Spezialisierung wäre mir viel zu einseitig. Ich bin begeistertes Mitglied der JHaS*, und ich interessiere mich auch für die politischen Belange der Hausarztmedizin. Ich möchte versuchen, eine gute Hausärztin zu werden. Dazu brauche ich eine gute Weiterbildung, die mir alles mitgibt, was ein guter Hausarzt benötigt.

Beide Statements stammen von mir. Aber was hat zu dieser 180-Grad-Wende geführt? Im ersten Studienjahr hatte ich noch sämtliche Vorurteile (oder vielmehr Fehlurteile), die es über den Hausarztberuf gibt. Meine Vorstellung war ein Patchwork aus abschätzigen Kommentaren von Kollegen, verzerrten Medienbildern und dem Kontakt zu zwei ausgebrannten Hausärzten, die ich nur klagen hörte. Es hat viele Erfahrungen in Spital und Praxis sowie Gespräche gebraucht, um mir die Augen zu öffnen und zu zeigen, wie vielfältig, komplex und schön die Hausarztmedizin ist: ein bisschen von jedem Fachbereich, ein bisschen sein eigener Chef sein, eine wirkliche Patientenbeziehung, immer wieder die eigene Grenze ausloten, nicht eine Krankheit, sondern einen Menschen im Wartezimmer haben und zwischendurch Erholung beim Blutdruckmessen.

In den Hausarztpraktika im Studium habe ich erkannt, dass hinter jedem Blutdruck ein Mensch mit einer Geschichte steckt; spannende und berührende Geschichten. Im Spital fehlt der Rahmen, ihnen zuzuhören. Die vertiefte Beziehung die ein Hausarzt zu seinen Patienten hat, schafft erst die Möglichkeit, mehr zu erfahren. Auch der Zusammenhang zwischen Lebensumständen und Krankheiten und die Auswirkung von Krankheiten auf die ganze Familie sind Themen, die mich faszinierten. Dann traf ich in den Praktika beim Hausarzt immer wieder auf Krankheitsbilder, die ich in der Hausarztpraxis gar nicht erwartet hätte. Mir war nicht bewusst, dass auch ein Hausarzt auf Multiple Sklerose, Sarkoidose und Lupus stossen kann. Dass diese Patienten nicht nur beim Spezialisten sind, sondern auch der Hausarzt eine wichtige Ansprechperson sein kann. Ich habe bemerkt, dass ich mich als Hausärztin nicht einschränken muss. Alle Fächer sind vertreten und auch wenn ein Krankheitsbild selten ist oder das tägliche Brot eines anderen Spezialisten, bin ich als Hausärztin damit konfrontiert.

Was das Jammern angeht, habe ich neue positive Eindrücke am Arosakongress sammeln können. Dort fand ich Hausärzte, die nach vielen Jahren Tätigkeit noch Freude am Beruf haben. Ich lernte die Vielfalt der Praxismodelle und der «medizinischen Hobbies» kennen; getragen von spürbarer Begeisterung und Motivation. Schliesslich fand ich auch den Weg zur JHaS und zum BIHAM (Berner Institut für Hausarztmedizin, www.biham.unibe.ch) anlässlich des Hausarzt-Treffs $^{* \star}$. Ich traf auf viele Gleichgesinnte, das gab mir Gelegenheit, mich auszutauschen, und ich begann mich vermehrt für Politisches zu interessieren.

Hausarztmedizin ist also keine Unterforderung, sondern eine Herausforderung. Und ich hoffe sehr, dass dies künftig im neuen Weiterbildungsprogramm berücksichtigt wird. Ich möchte nicht, dass dieser tolle Beruf hinter dem Klischee des leicht zu habenden Facharzttitels und dem steten Plan B versinkt und noch mehr Erstjahresstudenten Hausarztmedizin ausschliessen, noch bevor sie überhaupt wissen, um was es geht. Auch die Patienten haben gutausgebildete und motivierte Ärzte verdient.

Ändere ich meine Meinung noch einmal? Ich möchte dies nicht ausschliessen. Aber bei aller Begeisterung, die ich für andere Spezialisierungen teilte, wirklich zufrieden bin ich erst mit dem Gedanken, Hausärztin zu werden.

\section{Wo trifft man zukünftige Hausärztinnen und -ärzte?}

Am 1. JHaS-Kongress am 2. April 2011 im Alten Spital Solothurn!

Studierende, Assistenzärzte, junge Hausärzte und Interessierte sind eingeladen, an Vorträgen und Workshops ihre Fertigkeiten für diesen spannenden Beruf zu erlernen und aufzufrischen. Eine gute Gelegenheit, zukünftige Kolleginnen und Kollegen zu treffen und am Abend gemeinsam zu feiern. Hauptprogramm und Anmeldung unter www. congress-info.ch/jhas2011 oder www.jhas.ch 